\title{
First Oral Short-course Treatment for Adults with Highly Active Relapsing Multiple Sclerosis Now Approved in Europe
}

An expert interview with Gavin Giovannoni

Blizard Institute, Barts and The London School of Medicine and Dentistry, Queen Mary University of London, UK

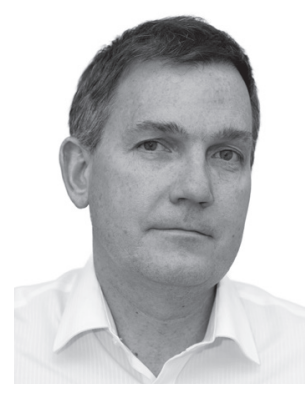

\begin{abstract}
Gavin Giovannoni
Gavin Giovannoni is Professor of Neurology, Blizard Institute, Barts and The London School of Medicine and Dentistry, Queen Mary University London and the Department of Neurology, Barts Health NHS Trust. His clinical interests are multiple sclerosis (MS) and other inflammatory disorders of the central nervous system. He is particularly interested in clinical issues related to optimising MS disease modifying therapies. His current research is focused on Epstein Barr virus as a possible cause of MS, defining the 'MS endophenotype', MS related neurodegeneration, MS biomarker discovery and MS clinical outcomes. His team focus on translational research and therefore have an active clinical trial programme.
\end{abstract}

\section{Keywords}

Multiple sclerosis, cladribine tablets

Disclosure: Gavin Giovannoni has received compensation for serving as a consultant or speaker for, or has received research support from: AbbVie, Almirall, Atara Bio, Bayer Schering Healthcare, Biogen Idec, Canbex, Eisai, Elan, Fiveprime Therapeutics, Genzyme, Genentech, GlaxoSmithKline, Ironwood Pharmaceuticals, Merck-Serono, Novartis, Pfizer, Roche, Sanofi-Aventis, Synthon BV, Teva Pharmaceutical Industries, UCB and Vertex Pharmaceuticals. This is an expert interview and as such, has not undergone the journal's standard peer review process.

Acknowledgements: Editorial assistance was provided by Katrina Mountfort, Freelance Writer, and was supported by Touch Medical Media.

Authorship: All named authors meet the International Committee of Medical Journal Editors (ICMJE) criteria for authorship of this manuscript, take responsibility for the integrity of the work as a whole, and have given final approval to the version to be published.

open Access: This article is published under the Creative Commons Attribution Noncommercial License, which permits any non-commercial use, distribution, adaptation and reproduction provided the original author(s) and source are given appropriate credit.

Received: 3 October 2017

Published Online: 4 December 2017

Citation: European Neurological Review, 2017;12(2):66-7

Corresponding Author: Gavin Giovannoni, Blizard Institute, Barts and The London School of Medicine and Dentistry, Queen Mary University London, 4 Newark Street, London E1 2AT, UK. E: g.giovannoni@qmul.ac.uk

Support: No funding was received in the publication of this article. $n$ recent years, a number of novel disease-modifying therapies have been approved for the treatment of patients with multiple sclerosis (MS). Cladribine tablets (Mavenclad'M ${ }^{\mathrm{T}}$, Merck), a purine nucleoside analogue, has been used for the treatment of several neoplasms ${ }^{1}$ and, in the last 15 years, has been developed for the treatment of MS. The clinical development of cladribine tablets has encountered a number of setbacks but in June 2017, the European commission granted marketing authorisation for cladribine tablets for the treatment of relapsing-remitting MS (RRMS) in patients with high disease activity. ${ }^{2}$ Approval was based on more than 10,000 patient years of data with more than 2,700 patients included in the clinical trial programme and more than 10 years of observation in some patients. In September 2017, cladribine tablets became available for patients with MS in the UK and Ireland. In an expert interview, Gavin Giovannoni, discusses this new addition to the treatment armamentarium for RRMS.

\section{Q: What are the advantages of cladribine tablets over other oral disease-modifying therapies for MS?}

The most important advantage is in the way in which the tablets are administered. They are not a maintenance treatment and therefore do not have to be given continuously. They are administered in short courses, and cause the immune system to be depleted and reconstituted through a unique mechanism, targeting the lymphocyte population, particularly B lymphocytes. When the immune system is reconstituted, the autoimmune response that underlies MS is suppressed, resulting in an immune system that is competent in terms of fighting infections, immune surveillance for malignancies and for generating immune responses to novel infections and vaccines. The incidence of potential long-term side effects is therefore likely to be low. This minimizes the risk of secondary autoimmune disease when the immune system reconstitutes, unlike alemtuzumab, which has a long-term risk of secondary autoimmune disease in $45-50 \%$ of patients; necessitating routine monthly monitoring for up to 4 years after the last course. Since cladribine tablets are given as short courses -5 days in month 1, 5 days in month 2, repeated a year later - there are up to 20 days of treatment over 2 years. The treatment effect persists into years 3 and 4 in the majority of patients. 
Another advantage of cladribine is the fact that it is semi-selective. There are other immunotherapies that deplete the immune system but these tend to affect the entire immune system whereas cladribine selectively targets the lymphocyte population, not affecting innate immunity, so we don't see infections associated with other therapies in this class. The only infection that has been noted is recurrent herpes infections, particularly shingles, because cladribine suppresses the $\mathrm{T}$ lymphocyte population. This complication associated with cladribine is seen with almost all immunosuppressive therapies.

The most important advantage of cladribine tablets is their ease of use. The monitoring requirement for liver function tests and other blood tests is lower than other disease-modifying therapies (DMTS). This reduces the pressure on nursing staff. Patients do not need repeated visits to hospital, in contrast with other DMTs such as alemtuzumab where monthly visits are needed for blood and urine tests and possibly treatment modification based on the results of these tests.

\section{Q: What is the mechanism of action of cladribine tablets?}

Cladribine affects DNA metabolism. It is a chlorinated purine analogue; the chlorination prevents it from being broken down by adenosine deaminase. It enters the cell and becomes phosphorylated. The triphosphorylated form then becomes incorporated into DNA and kills cells by apoptosis. The intracellular ratio of kinases to phosphatases favours the accumulation of cladribine in lymphocytes. Hence it selectively depletes lymphocytes, particularly B cells, ${ }^{3}$ without having a significant impact on leucocytes. In addition, the kinetics of depletion is slow, occurring over months. By contrast, alemtuzumab causes cell Iysis within hours, resulting in side effects such as infusion site reaction, temperature and rash.

\section{Q: Could you tell us about the clinical development of cladribine tablets, leading to their recent approval in the UK and Ireland?}

Cladribine was originally an oncology product and was classified as a chemotherapy agent. The first submission for regulatory approval in 2011 only included one pivotal trial, the phase III CLAdRIbine Tablets treating MS orallY (CLARITY) trial. ${ }^{4}$ This submission was rejected based on a safety signal related to malignancies (4 cases of malignancies occurred in the cladribine study arm versus none in the placebo group). However, when compared with other DMTs, the rate of malignancies was as expected and the rate in the placebo arm was very low. More safety data has emerged since, including a second clinical trial, extension study and registry, which suggest that cladribine does not increase the incidence of malignancies over the expected background rate in the short term. ${ }^{5,6}$ In addition, further analysis of clinical data revealed that cladribine tablets are particularly beneficial in patients with highly active disease, having an impact on relapse and disability progression. Another important parameter, which is increasingly used in studies of MS therapies, is no evident disease activity (NEDA). In the CLARITY phase III study, NEDA was $47 \%$, which places cladribine among the DMTs with the highest efficacy.7-12

\section{Q: Which patients are likely to benefit most from treatment with cladribine?}

The patients who are likely to benefit most are treatment naïve patients with more active disease. The clinical studies involved patients with active MS in terms of having had a relapse in the last 2 years but also an MRI scan that showed high lesion load and/or gadolinium-enhancing lesions at baseline. Cladribine is also beneficial as a second- or third-line treatment in patients who have experienced disease breakthrough on other DMTs. ${ }^{13,14} \square$
1. Tortorella C, Rovaris M, Filippi M, Cladribine. Ortho Biotech Inc, Curr Opin Investig Drugs, 2001;2:1751-6.

2. Merck Serono Ltd, MAVENCLAD $10 \mathrm{mg}$ tablets, Summary of product characteristics, Available from: www.medicines.org.uk/ emc/medicine/34044 (accessed 9 October 2017).

3. Baker D, Marta M, Pryce G, et al., Memory B cells are majo targets for effective immunotherapy in relapsing multiple sclerosis, EBioMedicine, 2017;16:41-50.

4. Giovannoni G, Comi G, Cook S, et al., A placebo-controlled trial of oral cladribine for relapsing multiple sclerosis, N Eng/ J Med, 2010;362:416-26.

5. Comi G, Leist T, Freedman $\mathrm{M}$, et al., Efficacy of cladribine tablets in patients after conversion to clinically definite multiple sclerosis (CDMS): analysis of the ORACLE-MS study open-label maintenance period. Presented at: 3rd Congress of the European Association of Neurology (EAN), Amsterdam, The the European Association of Neurology (EAN),

6. Pakpoor J, Disanto G, Altmann DR, et al., No evidence for higher risk of cancer in patients with multiple sclerosis taking cladribine Neurol Neuroimmunol Neuroinflamm, 2015-2:e158.

7. Giovannoni G, Soelberg Sorensen P, Cook S, et al., Safety and efficacy of cladribine tablets in patients with relapsing-remitting multiple sclerosis: results from the randomized extension trial of the CLARITY study, Mult Scler, 2017; Epub ahead of print, doi:10.1177/1352458517727603

8. De Stefano N, Giorgio A, Battaglini M, et al. Reduced brain atrophy rates are associated with lower risk of disability progression in patients with relapsing multiple sclerosis treated with cladribine tablets, Mult Scler, 2017; Epub ahead of print, doi: $10.1177 / 1352458517690269$

9. Comi G, Cook SD, Giovannoni G, et al., MRI outcomes with cladribine tablets for multiple sclerosis in the CLARITY study, J Neurol, 2013;260:1136-46.

10. Ali S, Paracha N, Cook S, et al., Reduction in healthcare and societal resource utilization associated with cladribine tablets in patients with relapsing-remitting multiple sclerosis: analysis of economic data from the CLARITY study, Clin Drug Investig, 2012;32:15-27.

11. Giovannoni $G$, Cook S, Rammohan $K$, et al sustained diseaseactivity-free status in patients with relapsing-remitting multiple sclerosis treated with cladribine tablets in the CLARITY study: post-hoc and subgroup analysis, Lancet Neurol, 2011;10:329-37.

12. Cook S, Vermersch P, Comi G, et al., Safety and tolerability of cladribine tablets in multiple sclerosis: the CLARITY (CLAdRIbine Tablets treating multiple sclerosis orallY) study, Mult Scler, 2011;17:578-93

13. Rammohan K, Giovannoni G, Comi G, et al., Cladribine tablets for relapsing-remitting multiple sclerosis: efficacy across patient subgroups from the phase III CLARITY study, Mult Scler Relat Disord, 2012;1:49-54.

14. Alvarez-Gonzalez C, Adams A, Mathews J, et al., Cladribine to treat disease exacerbation after fingolimod discontinuation in progressive multiple sclerosis, Ann Clin Transl Neurol. 2017;4:506-11. 